\title{
A Comparative Study of the Methods of Speciation Using X-ray Absorption Fine Structure
}

\author{
A. Gaur* And B.D. Shrivastava \\ School of Studies in Physics, Vikram University, Ujjain 456010, India
}

(Received December 22, 2010; in final form July 14, 2011)

\begin{abstract}
Determination of the chemical forms along with the relative quantity of the different species in a given sample, termed as speciation, can be done by analyzing X-ray absorption fine structure spectra. The different methods that can be used for speciation are: principal component analysis, target transformation, methods based on derivative spectra, method based on the relative position of the absorption edge, residual phase analysis, normalized difference absorption edge spectra analysis and linear combination fitting. An attempt has been made to make a comparative study of these different methods of speciation by recording the X-ray absorption fine structure at the copper $K$-edge in a mixture having cuprous oxide and cupric oxide in a specific ratio. The X-ray absorption fine structure spectra of the two oxides have also been recorded separately and the different characteristic X-ray absorption near edge structure features have been identified and their origins have been discussed. Speciation of the mixture has been done using these different methods and the results obtained have been compared and discussed.
\end{abstract}

PACS: 78.70.Dm

\section{Introduction}

Speciation concerns identification and quantification of the different chemical species present in a sample. X-ray absorption spectroscopy (XAS) is an easy, reliable and widely used technique for speciation. While extended X-ray absorption fine structure (EXAFS) can be used to determine the local structure around the absorbing atom, i.e., bond distance, coordination number and chemical identity of the elements, the X-ray absorption near edge structure (XANES) can be used to provide information about oxidation state of an excited atom and its coordination symmetry. The main scientific issues concerning speciation ultimately depend on the molecular-scale structure of species. For speciation, one usually models XAFS spectra of the sample by using well-defined chemical species as standards. The analysis can be done both in the XANES and EXAFS regions. But analyzing the complex structure containing number of species using EXAFS is difficult. When the number of species is more than two and species are unknown, the parametrical analysis becomes practically impossible due to many parameters exceeding the number of allowed independent parameters. In such cases, the analysis of XANES plays an important role.

In a sample different chemical species may coexist and for speciation in such cases, several modeling techniques are useful [1]. The commonly used methods for the analysis of such samples are principal component analysis (PCA) [1-5] and linear combination fitting (LCF) method [6-10]. The other X-ray absorption spectroscopic methods in use are residual phase analysis (RPA) [11], target transformation (TT) method [1, 4], derivative spectra methods [12], method based on the relative posi-

* corresponding author; e-mail: abhijeetgaur9@gmail.com tion of the absorption edge [12] and normalized difference absorption edge spectra (NDAES) analysis [13-18]. In a preliminary report we have shown the usefulness of LCF and NDAES methods for speciation [19]. In the present work using a test case of a heterogeneous mixture of two oxides of copper, i.e., $\mathrm{CuO}$ and $\mathrm{Cu}_{2} \mathrm{O}$, we have tried to compare and evaluate all of the above mentioned methods of speciation. It is probably for the first time that such a comparison has been attempted.

\section{Experimental}

Pure $(99.99 \%) \mathrm{Cu}_{2} \mathrm{O}$ and $\mathrm{CuO}$ powders were mixed in the ratio of $3: 1$ by weight. Absorption screens were prepared of the finely powdered pure $\mathrm{Cu}_{2} \mathrm{O}$, pure $\mathrm{CuO}$ and their mixture. The X-ray absorption fine structure (XAFS) spectra for these absorption screens were recorded using the EXAFS setup at the synchrotron wiggler beamline $4-1$ at the Stanford Synchrotron Radiation Laboratory (SSRL), Stanford, California, USA. A double silicon crystal $\mathrm{Si}(111)$ was used as a monochromator. Harmonics were suppressed by detuning the crystal spectrometer. The XAFS data at the $K$-absorption edge of copper were obtained in the transmission mode at room temperature. Three ionization chambers were employed as detectors. In each case, $\mathrm{Cu}$ metal foil spectra were recorded simultaneously for energy calibration. The energy of the first inflection point of the copper metal $K$ absorption edge was taken as $8979 \mathrm{eV}$ for this purpose.

\section{XANES features of the standards}

In the present study, EXAFS data analysis program Athena has been used for normalization [20]. This program includes AUTOBK for background removal. The normalized (energies normalized to the elemental $\mathrm{Cu}$ edge, baseline, and background corrected) XANES spectra of copper metal, cuprous oxide, cupric oxide, and 
their mixture are shown in Fig. 1. The edge position, defined as the maximum point of the first derivative function in the rapidly rising edge step of the absorbance vs. energy plot, have been found to be 8979.0, 8980.6, and $8983.6 \mathrm{eV}$ for $\mathrm{Cu}$ foil, $\mathrm{Cu}_{2} \mathrm{O}$, and $\mathrm{CuO}$, respectively. This shows increase in edge energy as the oxidation number increases, which is an established fact. Our values are the same as those reported by Kim and Lee [21]. The position of the $K$-absorption edge in the mixture is found to be at $8981.4 \mathrm{eV}$.

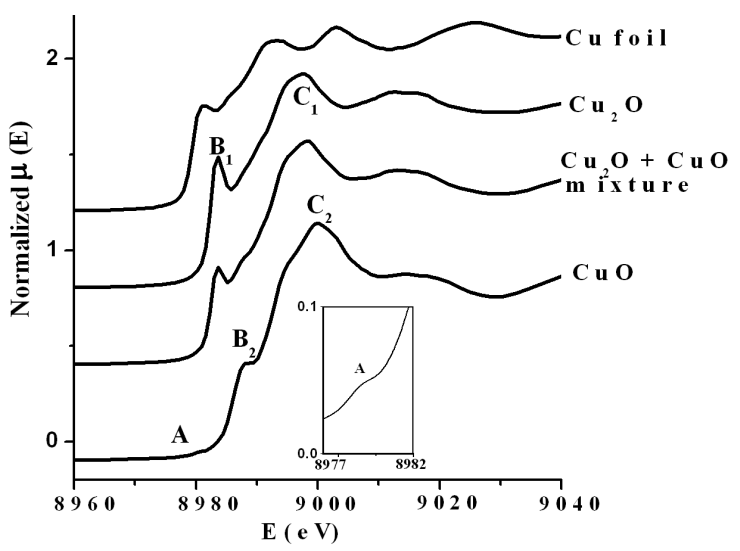

Fig. 1. XANES spectra of copper metal, cuprous oxide, cupric oxide, and their mixture.

The different characteristic features obtained in the present investigation in the XANES region for two copper oxides, which are used as standards, are also shown in Fig. 1. These features are important as they are ultimately used for speciation purpose and hence are discussed below in brief.

\section{1. $C u(I)$ oxide}

The $\mathrm{Cu} K$-edge XANES is assigned to the dipole allowed $1 s \rightarrow 4 p$ transition. In $\mathrm{Cu}(\mathrm{I})$ compounds, the $\mathrm{Cu} 4 p$ orbitals split into $4 p_{x y}$ and $4 p_{z}$ due to ligand field splitting. Hence, their XANES spectra exhibit two peaks, $B_{1}$ and $C_{1}$. Peak $B_{1}$ can be ascribed to the transition $1 s \rightarrow 4 p_{x y}$ and peak $C_{1}$ to the transition $1 s \rightarrow 4 p_{z}$. In copper(I) oxide each copper atom forms two collinear bonds with oxygen atoms. In the linear $\mathrm{Cu}(\mathrm{I})$ compound having two coordinated ligands, the antibonding copper $4 p_{z}$ molecular orbitals have higher energy than $4 p_{x y}$ orbitals due to the repulsive interaction between electrons along $z$ axis. The covalent ligand orbital overlap along $z$ axis reduces the intensity of the $1 s \rightarrow 4 p_{z}$ transition. Therefore, peak $B_{1}$ is intense and appears at lower energy than peak $C_{1}[13,21]$.

\section{2. $C u(I I)$ oxide}

While $\mathrm{Cu}(0)$ and $\mathrm{Cu}(\mathrm{I})$ have no hole in the $3 d$ orbital, $\mathrm{Cu}(\mathrm{II})$ compounds are in a $d^{9}$ configuration, thus a weak but characteristic pre-edge peak representing the quadrupole-allowed $1 s \rightarrow 3 d$ transition appears below the edge in most $\mathrm{Cu}(\mathrm{II})$ compounds. This characteristic pre-edge peak observed in most cupric compounds is denoted as "peak $A$ ". Therefore, the presence of peak $A$ could be regarded as a signature for a divalent copper together with a higher edge energy $E_{0}$ compared to those of $\mathrm{Cu}(0)$ and $\mathrm{Cu}(\mathrm{I})$ compounds [22]. The set of features falling between the labels $B_{2}$ and $C_{2}$ is dominated by the dipole-allowed transitions to $\mathrm{Cu} 4 p$-like final states which split into $4 p_{x y}$ and $4 p_{z}$ states. The feature $B_{2}$ observed as a shoulder in the plot of XANES for $\mathrm{CuO}$ is attributed to transitions to the $4 p_{x y}^{*}$ state. The asterisk sign indicates that the transition $1 s \rightarrow 4 p_{x y}$ is accompanied by a shake-down transition associated with charge transfer from ligand to the metal. The peak $C_{2}$ at the top of the edge is attributed to the transition to $4 p_{z}$ states [22].

\section{Data analysis, results and discussions}

In the present study, for PCA and target transformation, SIXPack data analysis software has been used. (Details can be found at www.ssrl.slac.stanford.edu/swebb/ sixpack.htm .) LCF has been performed using Athena. The position of the edge corresponding to the point having $\mu x=0.5$ in the normalized spectrum has been determined using Athena. The difference spectra and the derivative spectra for the analysis were also constructed using Athena. EXAFS data analysis program Artemis has been used for optimizing the theoretical model to the measured spectrum [20]. This program includes FEFF6L for generation of the theoretical EXAFS models, and FEFFIT for parameter optimization of the model [6].

By applying PCA and target transformation the number and identity of components in the mixture have been confirmed. Then, five methods have been used by us for determining the proportions of the $\mathrm{CuO}$ and $\mathrm{Cu}_{2} \mathrm{O}$ in the mixture. The methods of speciation and the results obtained are discussed below.

\subsection{Principal component analysis}

PCA determines the minimum number of significant components required to satisfactorily regenerate the data matrix, using a reduced space. PCA assumes that the absorbance in a set of spectra can be mathematically modeled as a linear sum of individual components, called factors, which correspond to each one of the species present in the sample, plus noise [3]. The two main outputs from PCA are eigenvalues and eigenvectors [1]. PCA has been performed in both XANES and EXAFS regions. However, the results of PCA have been presented in Fig. 2 only for the EXAFS region in the range 2 to $12 \AA^{-1}$. The figure shows the different components weighted by their eigenvalues [5]. It can be seen from the figure that the first two components clearly dominate the spectra and the third component appears to be noise.

\subsection{Target transformation}

In target transformation, which is also known as transformation factor analysis (TFA), the spectra from reference compounds are individually compared with the collection of mathematical PCs. The experimental reference 


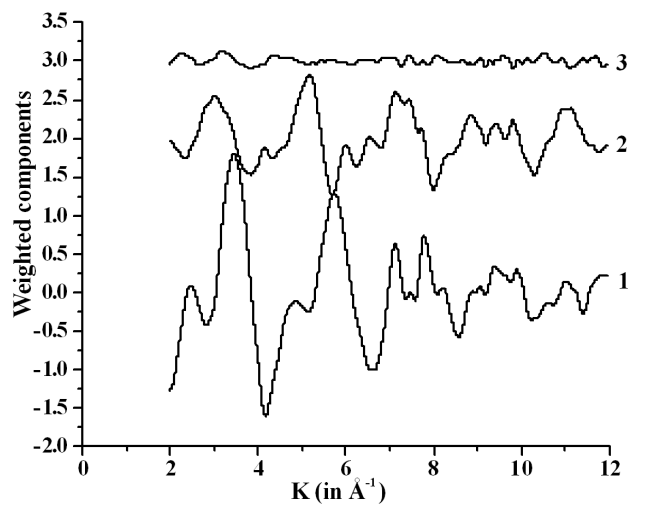

Fig. 2. First three components from PCA calculation performed in the EXAFS region and weighted by eigenvalues.

spectra are transformed to fit the number of PCs selected from PCA. The degree to which the reference must be changed to fit the PCs is measured by SPOIL value [1]. A high SPOIL value indicates a poor fit, suggesting that this standard is not well represented in the collection of sample spectra (represented by the PCs) [4]. Target transformation has been performed in both XANES and EXAFS regions. However, the results of TT have been presented in Fig. 3 only for the EXAFS region in the range 2 to $12 \AA^{-1}$. One of the standards, i.e., copper metal has been rejected as a potential target because its SPOIL value has come out to be $>6$. $\mathrm{Cu}_{2} \mathrm{O}$ has proved to be a very good target, with a SPOIL value $<3$ and $\mathrm{CuO}$ has come out as marginal candidate in the SPOIL test, with SPOIL value between 3 and 6 .
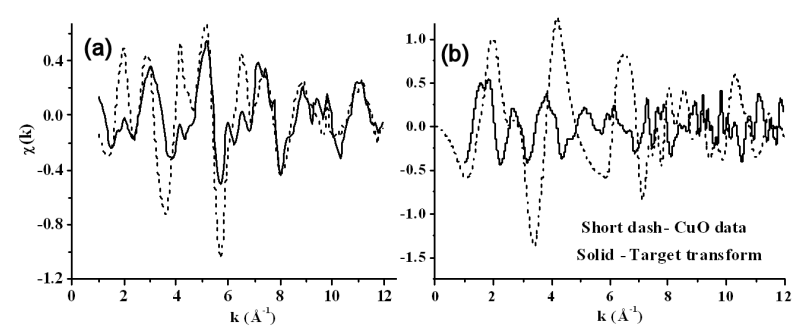

Fig. 3. Predicted targets obtained through target transformation of the $\mathrm{Cu} K$-edge EXAFS spectra for (a) $\mathrm{Cu}_{2} \mathrm{O}$ and (b) $\mathrm{CuO}$.

\subsection{Method based on derivative spectra}

The derivative spectra of the mixture and the standards $\mathrm{Cu}_{2} \mathrm{O}$ and $\mathrm{CuO}$ are shown in Fig. 4. The derivative spectrum of a mixture has a distinct feature: " $\gamma$ " at $8981 \mathrm{eV}$ corresponding to the $\mathrm{Cu}(\mathrm{I})$ component. It is the most intense feature of the derivative XANES spectra of $\mathrm{Cu}(\mathrm{I})$ species and can be used to determine the percentage of a species in the mixture. Also, it lies in a region (from 8980 to $8984 \mathrm{eV}$ ) where the $\mathrm{Cu}$ (II) species have a null derivative [12]. The intensity of this peak varies as the amount of $\mathrm{Cu}(\mathrm{I})$ species is varied. If $I_{\mathrm{m}}$ and $I_{\mathrm{Cu}_{2} \mathrm{O}}$ are the intensities of the first maximum in the derivative spectra at $8981 \mathrm{eV}$ in the mixture and $\mathrm{Cu}_{2} \mathrm{O}$ respectively, then the ratio of $I_{\mathrm{m}}$ to $I_{\mathrm{Cu}_{2} \mathrm{O}}$ gives the fraction of $\mathrm{Cu}(\mathrm{I})$ in the mixture. The percentages of $\mathrm{Cu}_{2} \mathrm{O}$ and $\mathrm{CuO}$ in the mixtures as obtained from this method are $74 \%$ and $26 \%$, respectively, with an error of $\pm 2 \%$.

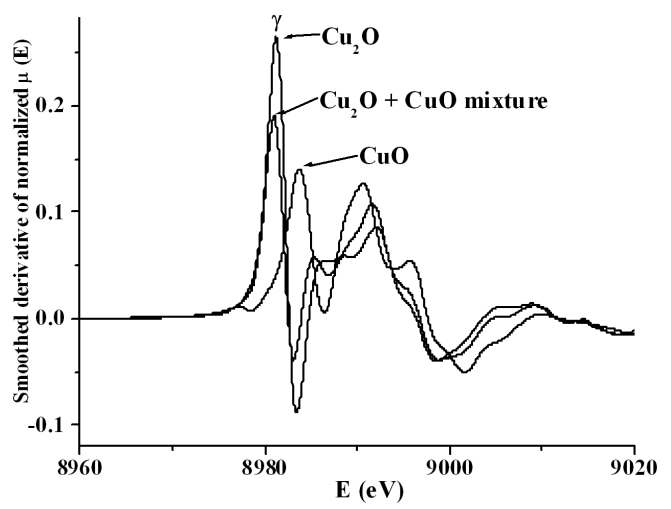

Fig. 4. First derivatives of XANES region for $\mathrm{Cu}_{2} \mathrm{O}$, $\mathrm{CuO}$ and their mixture. Feature $\gamma$ corresponds to the $\mathrm{Cu}(\mathrm{I})$ component. The height of this feature has been used to determine the percentage of $\mathrm{Cu}(\mathrm{I})$ in the mixture.

\subsection{Method based on position of the edge}

It is well known that position of the absorption edge varies with the oxidation state of central metal atom. Also, significant difference between the positions of the $\mathrm{Cu} K$-edges of $\mathrm{Cu}(\mathrm{I})$ and $\mathrm{Cu}(\mathrm{II})$ has been observed. In a mixture the position of the $\mathrm{Cu} K$-edge is between the positions of the edges of $\mathrm{Cu}(\mathrm{I})$ and $\mathrm{Cu}(\mathrm{II})$. This shift in the value of edge energy of the mixture with respect to $\mathrm{Cu}(\mathrm{I})$, can be used to measure percentage of $\mathrm{Cu}(\mathrm{II})$ present in the mixture.

For this method, Lamberti et al. [12] have defined the position of the edge as the point corresponding to $\mu x=0.5$ in the normalized spectrum. Writing $E_{\mathrm{Cu}_{2} \mathrm{O}}$, $E_{\mathrm{CuO}}$ and $E_{\mathrm{m}}$ as the energies of the position of the edge in $\mathrm{Cu}_{2} \mathrm{O}, \mathrm{CuO}$, and the mixture respectively, the fraction $x_{\mathrm{m}}$ of $\mathrm{Cu}(\mathrm{II})$ in the mixture can be determined from relation: $x_{\mathrm{m}}=\Delta E_{\mathrm{m}} / \Delta E_{\mathrm{CuO}}$, where $\Delta E_{\mathrm{m}}=E_{\mathrm{m}}-E_{\mathrm{Cu}_{2} \mathrm{O}}$ and $\Delta E_{\mathrm{CuO}}=E_{\mathrm{CuO}}-E_{\mathrm{Cu}_{2} \mathrm{O}}$ are the edge energy shifts with respect to $\mathrm{Cu}_{2} \mathrm{O}$. The percentages of $\mathrm{Cu}_{2} \mathrm{O}$ and $\mathrm{CuO}$ in the mixtures as determined from this method are $79 \%$ and $21 \%$, with an error of $\pm 5 \%$.

\subsection{Normalized difference absorption edge analysis}

In this method, to quantify copper content, the normalized difference edge absorption spectra have been calculated by subtracting normalized edge of $\mathrm{Cu}$ (II) from that of normalized edge of the $\mathrm{Cu}(\mathrm{I})$ which produces characteristic derivative shaped spectra. The difference spectrum has a positive peak at $8983-8984 \mathrm{eV}$ and a broad negative feature at $8990-9000 \mathrm{eV}$. The amount of cuprous 
ion present can be determined from the height of the positive peak [13]. In other elements, similar characteristic features are present which can be used for the purpose of speciation [15].

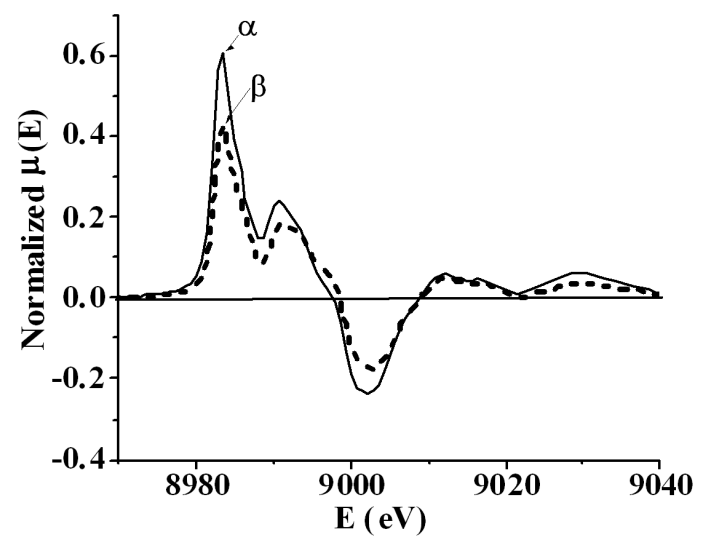

Fig. 5. Normalized difference absorption edge spectra for copper $K$-edge XANES. Solid line curve has been obtained by subtracting $\mathrm{CuO}$ spectra from $\mathrm{Cu}_{2} \mathrm{O}$ spectra of Fig. 1. Similarly, short dashed line curve has been obtained by subtracting $\mathrm{CuO}$ spectra from the spectra of mixture of $\mathrm{Cu}_{2} \mathrm{O}+\mathrm{CuO}$ of Fig. 1. The ratio of the height of positive peak $\beta$ to that of peak $\alpha$ gives the proportion of $\mathrm{Cu}(\mathrm{I})$ in the mixture.

The results of NDAES are shown in Fig. 5. In this figure, $\alpha$ is the positive peak obtained when $\mathrm{CuO}$ spectrum is subtracted from $\mathrm{Cu}_{2} \mathrm{O}$ spectrum and $\beta$ is obtained when the spectrum of mixture is subtracted from the $\mathrm{Cu}_{2} \mathrm{O}$ spectrum. The heights of the peaks $\beta$ and $\alpha$ have been measured very precisely. The ratio of the height of positive peak $\beta$ to that of peak $\alpha$ gives the proportion of $\mathrm{Cu}(\mathrm{I})$ in the mixture. The percentages of $\mathrm{Cu}_{2} \mathrm{O}$ and $\mathrm{CuO}$ in the mixture, as determined from this method are $71 \%$ and $29 \%$, respectively, with an error of $\pm 5 \%$.

\subsection{Residual phase analysis}

The details of RPA have been given by Frenkel et al. [11]. It utilizes one of the known components as a "starting phase". The "starting phase" is then fractionated and iteratively subtracted from the total EXAFS signal to produce corresponding residual spectra. The individual residual spectra are analyzed to obtain the best fit as follows.

Taking pure $\mathrm{Cu}_{2} \mathrm{O}$ EXAFS data as the known phase and the EXAFS data of mixture as total EXAFS signal, the residual phase data has been constructed [11], for all $y$ (adjustable mixing fraction) between 0 and 1 , with an increment of 0.1. The difference spectra have been constructed using Athena. After obtaining the residuals, the fitting of residual data have been done using Artemis. For this fitting crystallographic data of $\mathrm{CuO}$ has been used as input. The parameters which have been varied during the fitting include the passive electron reduction factor $\left(S_{0}^{2}\right)$, the number of identical paths $\left(N_{\mathrm{i}}\right)$, the relative mean-square displacement of the atoms included in path $\left(\sigma_{\mathrm{i}}^{2}\right)$, an energy shift for each path $\left(\Delta E_{0}\right)$, and a change in the path length $\left(\Delta R_{m i}\right)$. The statistical chi-square values obtained in each fit were then plotted as the function of $y$, and the minimum has been obtained as shown in Fig. 6. The corresponding mixing fraction is found from the position of the minimum. The percentages of $\mathrm{Cu}_{2} \mathrm{O}$ and $\mathrm{CuO}$ in the mixture have thus been found to be $70 \%$ and $30 \%$, respectively, with an error of $\pm 5 \%$.

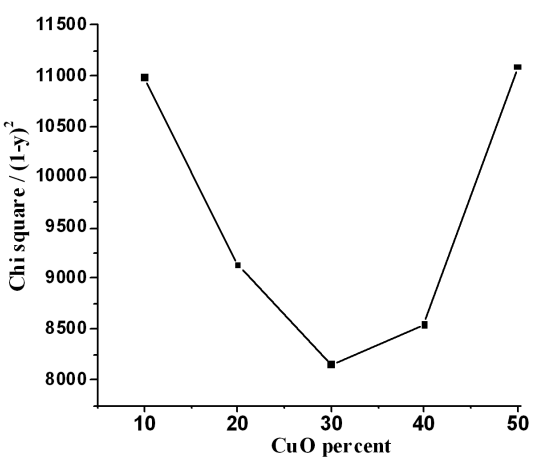

Fig. 6. Reduced statistical chi square obtained by varying the percentage of $\mathrm{CuO}$ using RPA performed in EXAFS region.

\subsection{Linear combination fitting}

In least-squares LCF, one determines the proportions of the spectra for selected standards that, when summed, yield the least fit to the spectrum for an unknown sample. Also, least-squares LCF can be done across a wide energy range of the spectrum, i.e., even in the EXAFS region and thus enhances the discrimination of different species having identical spectral features at a given energy but distinct features at other energies [6].

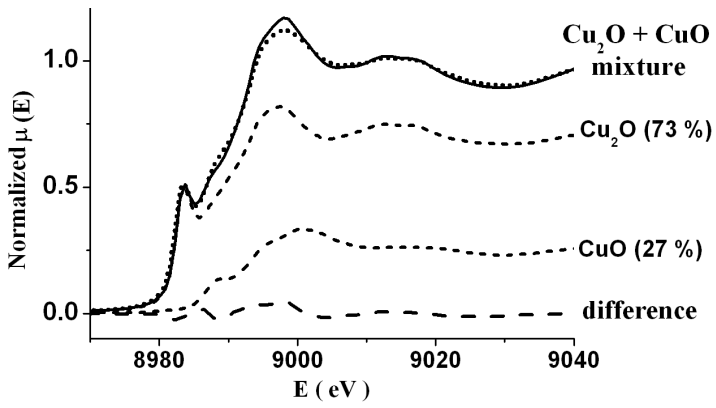

Fig. 7. Results of the LCF for copper $K$-edge XANES spectra of mixture of $\mathrm{Cu}_{2} \mathrm{O}$ and $\mathrm{CuO}$. Solid and dotted lines denote experimental and LC fit data, respectively. Fractions of $\mathrm{Cu}_{2} \mathrm{O}$ and $\mathrm{CuO}$ making up the fitted spectra are shown by short dashed line. The goodness-of-fit between experimental data and the LC fit data can be seen from the little difference between the two data, plotted as dashed line curve.

The results of LCF are shown in Fig. 7. The fractions of the $\mathrm{Cu}_{2} \mathrm{O}$ and $\mathrm{CuO}$ making up the fitted spectra are 
also shown in this figure. The percentages of $\mathrm{Cu}_{2} \mathrm{O}$ and $\mathrm{CuO}$ in the mixture, as determined from LCF method are $73 \%$ and $27 \%$, respectively, with an error of $\pm 2 \%$. In the case of LCF method, $R$-factor and chi-square values are 0.00016 and 0.02309 , respectively. The little difference between the experimental data and LC fitted data can be seen from the difference curve which is also shown in Fig. 7.

It may be mentioned here that Figs. 5 and 7 are identical to those reported in our earlier paper [19] which also gives the results of LCF and NDAES methods. These have been repeated here to make the present paper complete in itself and to make available all the methods at one place.

\section{Conclusions}

In this study, PCA has been first performed to define the number of significant components in the normalized spectra of the mixture. Target transformation has then been used to examine if the proposed standards $\left(\mathrm{Cu}_{2} \mathrm{O}\right.$ and $\left.\mathrm{CuO}\right)$ were present in the mixture. Then speciation has been done by five different methods, namely, derivative spectra method, edge position method, NDAES, RPA, and LCF. The percentages of the components, $\mathrm{Cu}_{2} \mathrm{O}$ and $\mathrm{CuO}$, in the mixture as obtained by these five methods are summarized in Table. A comparison of the results obtained from these methods with the as prepared composition shows that LCF and derivative spectra method appear to be more accurate than other methods of speciation under consideration, as these two methods give results close to the as prepared percentages of the components in the mixture. However, LCF is much informative as it can be executed across a wide energy range of the spectrum, i.e., even in the EXAFS region.

Results of speciation.

TABLE

\begin{tabular}{c|c|c|c|c}
\hline \hline \multirow{2}{*}{$\begin{array}{c}\text { Sample } \\
\text { No. }\end{array}$} & \multirow{2}{*}{$\begin{array}{c}\text { Method of } \\
\text { speciation }\end{array}$} & \multicolumn{3}{|c}{$\begin{array}{c}\text { Percentages of components } \\
\text { in the mixture }\end{array}$} \\
\cline { 3 - 5 } & & $\mathrm{Cu}_{2} \mathrm{O}$ & $\mathrm{CuO}$ & Max. \% error \\
\hline 1. & LCF & 73 & 27 & $\pm 2 \%$ \\
2. & NDAES & 71 & 29 & $\pm 5 \%$ \\
3. & RPA & 70 & 30 & $\pm 5 \%$ \\
4. & der. Cu(I)* & 74 & 26 & $\pm 2 \%$ \\
5. & edge** & 79 & 21 & $\pm 5 \%$ \\
\hline \multicolumn{2}{c}{ as prepared } & 75 & 25 & - \\
\hline
\end{tabular}

* Method based on derivative spectra of $\mathrm{Cu}(\mathrm{I})$ component.

** Method based on position of the edge.

From the present comparative study of the methods of speciation, PCA has been found to be ideal method to identify the number of independent components that constitute the sample spectra. Further, target transformation can be used to rank and identify the most likely standards. LCF has been found to be better method as compared to other methods for finding the percentages of the components in the sample, but it can be applied only when the components have been identified. Four other methods: NDAES, RPA, derivative spectra method, and edge position method can also be used for this purpose. In case of complex matrices, e.g., soil in which many different chemical forms of the element may coexist, the modeling techniques such as PCA and target transformation are more convenient to use [23, 24]. RPA is suitable for the X-ray absorption spectroscopic analysis of complex and dynamic systems such as metalloenzymes [11].

\section{Acknowledgments}

Thanks are due to Prof. E.A. Stern for recording the spectra at Stanford Synchrotron Radiation Laboratory (SSRL), Stanford, California, USA along with one of the authors (B.D.S.). Thanks are due to Madhya Pradesh Council of Science \& Technology (MPCST), Bhopal (India) for a research grant.

\section{References}

[1] S. Beauchemin, D. Hesterberg, M. Beauchemin, Soil Sci. Soc. Am. 66, 83 (2002).

[2] E.R. Malinowski, Factor Analysis in Chemistry, Wiley, New York 1991.

[3] D. Bazin, J.J. Rehr, J. Phys. Chem. B 107, 12398 (2003).

[4] J.M. Seiter, K.E. Staats-Borad, M. Ginder-Vogel, D.L. Sparks, J. Environ. Qual. 37, 477 (2008).

[5] Q. Wang, J.C. Hanson, A.I. Frenkel, J. Chem. Phys. 129, 234502 (2008).

[6] S.D. Kelly, D. Hesterberg, B. Ravel, Methods of Soil Analysis, Part 5, Mineralogical Methods, Soil Science Society of America, Medison, 2008, Ch. 14.

[7] B. Ajiboye, O. Akinremi, A. Jurgensen, Soil. Sci. Soc. Am. 71, 1288 (2007).

[8] A.J. Berry, A.C. Hack, J.A. Mavrogenes, M. Newville, S.R. Sutton, Am. Mineralogist 91, 1773 (2006).

[9] M. Takaoka, T. Yamamoto, A. Shiono, N. Takeda, K. Oshita, T. Matsumoto, T. Tanaka, Chemosphere 59, 1497 (2005).

[10] X.C. Kretschmer, G. Meitzner, J.L. Gardea, R. Webb, Appl. Environm. Microbiol. 70, 771 (2004).

[11] A.I. Frenkel, O. Kleifeld, S.R. Wasserman, I. Sagi, J. Chem. Phys. 116, 9449 (2002).

[12] C. Lamberti, S. Bordiga, F. Bonino, C. Prestipino, G. Berlier, L. Capello, F. D'Acapito, F.X. Xamena, A. Zecchina, Phys. Chem. Chem. Phys. 5, 4502 (2003).

[13] L.S. Kau, D.J. Spira-Solomon, J.E. Penner-Hahn, K.O. Hodgson, E.I. Solomon, J. Am. Chem. Soc. 109 6433 (1987).

[14] L.S. Kau, J.E. Penner Hahn, E.I. Solomon, K.O. Hodgson, J. Phys. (France) 47, C8 1177 (1986).

[15] G. Liang, Y. Guo, D. Badresingh, W. Xu, Y. Tang, M. Croft, J. Chen, A. Sahiner, O. Beom, J.T. Markert, Phys. Rev. B 51, 1258 (1995). 
[16] J.E. Penner-Hahn, K.O. Hodgson, D.J. Spira, E.I. Solomon, Biochem. Biophys. Res. Commun. 112, 737 (1983).

[17] J.E. Penner-Hahn, B. Hedman, K.O. Hodgson, D.J. Spira, E.I. Solomon, Biochem. Biophys. Res. Commun. 119, 567 (1984).

[18] J.M. Tranquada, S.M. Heald, A.R. Moodenbaugh, G. Liang, M. Croft, Nature 337, 720 (1989).

[19] A. Gaur, B.D. Shrivastava, S.K. Joshi, J. Phys., Conf. Series 190, 012084 (2009).

[20] B. Ravel, M. Newville, J. Synchroton Rad. 12, 537 (2005).
[21] W.B. Kim, J.S. Lee, J. Phys. Chem. B 107, 9195 (2003).

[22] C.H. Chou, I.N. Lin, Chin. J. Phys. 29, 263 (1991).

[23] D.G. Strawn, L.L. Baker, Environm. Pollut. 10, 2813 (2009).

[24] S. Legros, P. Chaurand, J. Rose, A. Masion, V. Briois, J.H. Ferrasse, H.S. Macary, J.Y. Bottero, E. Doelsch, Environ. Sci. Technol. 44, 6926 (2010). 